\title{
Establishment and Application of Standardized Communication Mode for Renal Puncture
}

\author{
Jinglin Zhou ${ }^{1, ~ a, ~ L i a n z h i ~ Y a n g ~}{ }^{2, ~ b}$, Qi Jiang ${ }^{3, ~ c}$, and Zhengping Qu ${ }^{4, *}$ \\ ${ }^{1}$ School of Nursing, Changchun University of Chinese Medicine, Changchun 130001, China. \\ ${ }^{2}$ Stomatology Department, Changchun University of Chinese Medicine Affiliated Hospital, Changchun \\ 130001, and China. \\ ${ }^{3}$ Department of Nephrology, China-Japan Union Hospital of Jilin University, Changchun 130001, China. \\ ${ }^{4}$ Nursing Training and Research Department, Changchun University of Chinese Medicine Affiliated Hospital, \\ Changchun 130001, China. \\ a568115025@qq.com, ${ }^{\text {b7} 715195624 @ q q . c o m, ~}{ }^{\mathrm{c}}$ zhoujinglin749@gmail.com \\ *Corresponding author email: qzp19961018@163.com
}

Keywords: CICARE Communication Mode; Nursing Care Quality; Compliance of Communication Process; Patient Satisfaction.

\begin{abstract}
Objective: To apply the CICARE communication mode to the preoperative communication of renal puncture, and to summarize the effect of application. Methods: Extracting 60 patients with CICARE communication in this study From January 2017 to December 2018.The patients were divided into observation group and control group. The control group was treated with traditional communication mode. The observation group was treated with CICARE communication mode. Compared the two groups of patients with compliance and satisfaction. Result: The compliance of the patient is better than the control group $(\mathrm{P}<0.05)$, and the satisfaction rate is higher than that of the control group $(\mathrm{P}<0.05)$. Conclusion: The communication mode of CICARE is helpful to the communication between the nurses and the patients, which improves the patients 'compliance and satisfaction, as well as the ability of nurses to communicate.
\end{abstract}

Renal needle biopsy, as a definitive diagnosis of an examination, has been widely carried out in clinical practice. The renal puncture is a traumatic examination, patients will have different degrees of psychological stress reaction, and these psychological stress reactions will interfere with preoperative exercise. Therefore, it is necessary for patients with targeted communication to enable patients to understand the operation and do a good job before the surgery to eliminate the patient's negative emotions. The CICARE communication mode is a process-oriented "C-I-CARE" communication mode [1] proposed by Los Angeles General Hospital of the University of California which is used in many countries to achieve good results. Since January 2017, our department nurses began to learn the CICARE communication mode and applied it into the patients with preoperative renal communication, which improved the patient's preoperative exercise compliance and patient satisfaction. The report is as follows:

\section{Materials And Methods}

\subsection{General Information}

A total of 60 patients were enrolled in one 3 grade hospital from January 2017 to December 2018, as a control group. A total of 60 patients From January 2017 to December 2018 were included in the experimental group. The inclusion criteria were as follows: aged from 18 to 65 years old, conscious and good communication skills. The renal needle biopsy surgery was operated under the guidance of color Doppler ultrasound. There was no significant difference in age, sex, educational level and payment rate between the two groups $(\mathrm{P}>0.05)$. As shown in Table 1 
TABLE 1. Comparison of two groups of patients with general information $(n=120)$

\begin{tabular}{|c|c|c|c|c|}
\hline Item & $\begin{array}{c}\text { Experimental } \\
\text { Group } \\
(n=60)\end{array}$ & $\begin{array}{c}\text { Control } \\
\text { Group(n=60) }\end{array}$ & X2value & $\mathrm{P}$ value \\
\hline \multicolumn{5}{|l|}{ Gender } \\
\hline Male & 38 & 33 & 0.535 & 0.353 \\
\hline Female & 22 & 27 & & \\
\hline Age (years) & $47.8 \pm 7.14$ & $46.9 \pm 7.31$ & 0.392 & 0.496 \\
\hline \multicolumn{5}{|l|}{ Education Level } \\
\hline $\begin{array}{l}\text { Under Middle } \\
\text { School }\end{array}$ & 17 & 18 & 0.196 & 0.841 \\
\hline $\begin{array}{l}\text { Middle School } \\
\text { and Above }\end{array}$ & 43 & 42 & & \\
\hline \multicolumn{5}{|l|}{ Pay Mode } \\
\hline \multicolumn{5}{|l|}{ Medical Insurance\& } \\
\hline $\begin{array}{l}\text { Rural cooperative } \\
\text { medical system }\end{array}$ & 51 & 52 & 0.291 & 0.793 \\
\hline Private Expense & 9 & 8 & & \\
\hline \multicolumn{5}{|l|}{ Marriage } \\
\hline Married & 49 & 48 & 0.171 & 0.812 \\
\hline Unmarried & 11 & 12 & & \\
\hline
\end{tabular}

\subsection{Methods}

Control group: According to the traditional method of communication, the responsibility nurses were arranged by the head nurse to the ward to the surgery patients with preoperative mission before 2 days. According to the contents of preoperative exercise and personal experience, nurses informed the patients the operation-related matters about needling surgery without special communication skills training. Observation group: CICARE communication mode was adopted to improve the preoperative communication. The application of CICARE communication mode for preoperative communication is as follows:

\subsubsection{Translation of CICARE Communication Mode}

Refer to the relevant domestic and international information, the CICARE communication mode is translated: (1) C connect: Appellation: for patients with appellation.(2) I: Introduction: introduce yourself (3) C: communication: communication with patients what need to do and how to do. (4) A: inquiry: the treatment obtained the consent of the patient. (5)R: answer: answering the questions of the patients and the family members. (6)E: leave: leave the patients[2].

\subsubsection{Combination of the CICARE communication mode and the quality of care services}

Quality care service is reflected in the six-step communication mode: 1)C: contact: natural expression, smile on the face. Do not call the names of the patients directly and use different appellation for different ages. (2)I: Introduction: introduce yourself by looking into the eyes of the patients directly, articulate clear, moderate speech speed, soft tone. The responsible nurses need to highlight the responsibility relationship with the patients when taking care of the patients before the surgery, so that the patients and the nurses can be in a friendly atmosphere. (3)C: communication: Nurses try to communicate with the straightaway words instead of professional terms when doing 
preoperative preparation and supine practice and observe the patient's response to the contents of preoperative practice. In the process, contrast some appropriate examples of successful examples and unsuccessful examples. (4)A: inquiry explanation: ask patients whether they understand the content of the education, and explain repeatedly what they do not understand until they have mastered it; (5) $\mathrm{R}$ :answer concerns: Listen to the questions raised by patients patiently. Nurses should be good at observing and listening to the patient's complaints and concerns, from which nurses can found the possible problems in the preoperative process and seize the problem. Take the appropriate measures to meet the needs of patients to solve the problems. Appropriate application of smiling, physical contact as well as psychological care should be included. Encourage patients to establish a good confidence in preoperative preparation. (6) E: leave: patients should be informed that they can communicate with the nurses at any time in the preoperative preparation process if they have questions. Do not walk too fast and close the door lightly.

\subsubsection{Pre-intervention Training}

CICARE communication mode and training of renal puncture before surgery Develop a six-step communication mode manual. All nurses in the department need to learn and master it. The mode should be drilled before the six-step communication mode is used. To improve the training effect, the responsibility groups will discuss these problems that exist in the mode and revise them in the form of group discussions. Responsibility groups applied PPT to the typical cases and learn in the form of examples to improve communication skills.

\subsection{Effect Evaluation}

\subsubsection{Nursing Compliance Survey}

Release of self-designed compliance questionnaire 2 days after the surgery according to the contents of preoperative communication. 6 items were included: diet, abdominal supine training, supine training, bed voiding, bed activities. The project was given 3,2,1 score separately according to compliance, part of the compliance and non-compliance. The content validity and internal consistency reliability need to be tested before using. The content validity was 0.896 and the Cronbach's a-value was 0.883 . The head of the nursing group asked the patients to fill the questionnaire in fact and recover it on the spot.

\subsubsection{Preoperative Visit Satisfaction of Patients}

Distribute the preoperative visit satisfaction questionnaire 2days after the surgery, including 6 items: the attitude of the nurses, appropriate communicate, the contents of the preoperative explanation, intraoperative key points, Postoperative attention and the communication satisfaction status of nurses. Three choices were given: very satisfied, satisfied, basic satisfied, not satisfied. The project was given with 4,3,2,1,score separately. The content validity and internal consistency reliability need to be tested before using. The content validity was 0.896 , Cronbach's a-value was 0.883. The patients filled in the table without their names according to their own feelings. The questionnaires should be handed on the spot. The ones with any unsatisfactory items were counted as dissatisfied questionnaires.

\subsection{Data Process}

The data were analyzed by SPSS19.0 statistical software package. The descriptive statistical analysis (mean, standard deviation, percentage)was included in the method, measurement data with $\mathrm{x}$ $\pm \mathrm{s}$, analysis with ridit. Count data was shown with relative number, test with $\mathrm{t} . \mathrm{P} \leq 0.05$ was statistically significant. 


\section{Results}

TABLE 2: 2 groups of patients with preoperative practice compliance comparison

\begin{tabular}{ccccc}
\hline & $\begin{array}{c}\text { Experimental } \\
\text { group }\end{array}$ & Control group & $\mathrm{t}$ & $\mathrm{p}$ \\
\hline Dietary & $1.32 \pm 0.64$ & $1.71 \pm 0.73$ & 0.753 & 0.005 \\
Ventral Decubitus & $1.12 \pm 0.78$ & $1.71 \pm 0.69$ & 0.932 & 0.003 \\
$\begin{array}{c}\text { Training } \\
\text { Supine Position Training }\end{array}$ & $1.29 \pm 0.66$ & $1.79 \pm 0.51$ & 0.975 & 0.003 \\
Urination Training in & $1.05 \pm 0.74$ & $1.45 \pm 0.62$ & 1.116 & 0.015 \\
$\begin{array}{c}\text { Bed } \\
\text { Bed Movement }\end{array}$ & $1.24 \pm 0.51$ & $1.62 \pm 0.48$ & 0.871 & 0.004 \\
\hline
\end{tabular}

TABLE 3: Comparison of two groups of patients with preoperative communication satisfaction

\begin{tabular}{ccccc}
\hline & $\begin{array}{c}\text { Experimental } \\
\text { group }\end{array}$ & Control group & $\mathrm{t}$ & $\mathrm{p}$ \\
\hline $\begin{array}{c}\text { Nurse Service Attitude } \\
\text { Appropriate communication } \\
\text { language of nurse }\end{array}$ & $2.71 \pm 0.68$ & $2.84 \pm 0.24$ & 3.361 & 0.035 \\
$\begin{array}{c}\text { communicates properly } \\
\text { Preoperative Explanation }\end{array}$ & $3.12 \pm 0.59$ & $3.65 \pm 0.81$ & 2.932 & 0.027 \\
$\quad$ Contents & $3.07 \pm 0.51$ & $3.36 \pm 0.53$ & 1.975 & 0.018 \\
Cooperate Points & $2.87 \pm 0.47$ & $3.27 \pm 0.76$ & 2.214 & 0.023 \\
\hline
\end{tabular}

\section{Discussion}

Renal biopsy surgery is a technology guided by the color doppler ultrasound to get access to the patient's kidney tissue samples safely, which is a clear diagnosis to guide the treatment through the sample for pathological examination. It was widely used clinically, because its trauma is small and it is easy to recover. At present, renal pathological examination has become an important indicator of kidney disease diagnosis. However, as an invasive examination, renal puncture has risks, like bleeding, urinary retention, back pain and infection. Patients require to be prone position for 2 hours, absolute bed 6hoursstrict and bedridden 24hours [3to reduce postoperative bleeding, Patients need to defecate on bed after surgery due to the changes in the supine position and drinking a lot of water. To adapt to the needs of postoperative supine and reduce the incidence of postoperative complications, the patients need to exercise prone position, supine position and voiding onbed1 day before. In the renal puncture, patients need to cooperate with the prone position and hold the breath. The patients need to understand the knowledge of the disease, Communicate with the patients patiently and listen to the patients for surgery concerns. Nurses need to explain the points of operation to the patients, so that patients may have the preparation for the surgery at all stages, which may avoid bad reactions by Informing the patients in the surgery.

CICARE communication mode has been effective in foreign applications. More and more attention has been paid to the mode which has the characteristics of shallow and deep interlocking [4]by the domestic nursing care industry. Apply the CICARE communication process which combined the CICARE communication mode with the quality of care services into the patients with renal biopsy before surgery, Table 2 statistics show that the compliance of the patients may improve significantly if nurses communicate with the patients according to the CICARE communication mode. Table 3 shows that the CICARE communication mode can improve the satisfaction of patients with renal puncture for nursing, which is consistent with improving the satisfaction of patients. The pattern of communication is conducive to the nurses to master the work, so that nurses know how to communicate gradually, which regulate the behavior of the nurses in nursing care[5]. In the process 
of communication, nurses communicate with patients with a smile and polite language, respecting for patients. Nurses introduce the purpose, methods, preparation and precautions of the body piercing surgery, getting the trust of patients at the same time. Patients and nurses are in a pleasant atmosphere to receive a variety of nursing knowledge, enhancing mutual trust, thereby it may increase the compliance of the preoperative patients with renal puncture and the satisfaction of nursing.

\section{Acknowledgments}

Project number: The Science and Technology Project of the 13th five-year Plan of the Department of Education of Jilin Province.(JJKH20181240KJ).

\section{References}

[1] Zhao Juan, Zhang Libing, Cheng Junxiang. Influence of process communication mode on satisfaction degree of nursing service for patients in psychiatric open wards[J].Chinese Nursing Research,2017,31(36):4715-4717.

[2] Yang Mei, Dong Xiaohong, Li Dan. The influence of CICARE communication mode on the satisfaction of inpatients [J].Today Nurse, 2018, 25 (12):173-175.

[3] Dong Zhenzhen, Sun Qicai, Zhang Ya. Study on CICARE Communication Mode in Nurse-Patient Communication in Operation Room[J].Hospital Management Forum,2019,36(5):31-33.

[4] Huang Yanzhu, Li Ling, Huang Haishan. Prospective study of CICARE standardized communication mode in improving the quality of clinical nursing service[J]Psychological Doctor,2018,24(27):269-271.

[5] Wu Peixuan. Application progress of CICARE communication mode in nursing practice[J].Medical frontier,2018,8(4):313-314. 